\title{
Comunicações: Manifesto sobre a qualidade das ques- tões de Física na Prova de Ciências da Natureza no Exame Nacional de Ensino Médio ${ }^{+*}$
}

\author{
Fernando Lang da Silveira \\ Instituto de Física - UFRGS \\ Porto alegre - RS \\ Jürgen Stilck \\ Instituto de Física - UFF \\ Rio de Janeiro - RJ \\ Marcia Barbosa \\ Instituto de Física - UFRGS \\ Porto alegre - RS
}

O Exame Nacional de Ensino Médio (Enem), que originalmente deveria servir para avaliar o ensino médio brasileiro, tem sido usado nos últimos anos como instrumento para entrada nas Universidades Federais e, neste sentido, tornou-se o instrumento que irá direcionar o ensino brasileiro, nos níveis fundamental e médio. No Enem, não existe uma prova de Física. Quinze questões (itens) de Física são encontradas, distribuídas ao acaso, entre as quarenta e cinco questões de Ciências da Natureza. A razão desta estrutura decorre da ideologia equivocada de que se deve fazer e se ensinar ciências de forma interdisciplinar. A ideologia da interdisciplinaridade, que não é adotada em países desenvolvidos como Estados

\footnotetext{
Manifesto on the quality of Physics questions of the Natural Science test in the National High School Exam (ENEM)

* Recebido: junho de 2014. Aceito: junho de 2014.
} 
Unidos e Inglaterra, se encontra presente no projeto de lei $\mathbf{6 8 4 0 / 2 0 1 3}$, reprovado pela diretoria da Sociedade Brasileira da Física .

Mais recentemente, a SBF emitiu uma carta aberta sobre o Enem e a qualidade das questões de Física que vai ao encontro do presente manifesto.

Apesar da alegada interdisciplinaridade nas Ciências da Natureza do Enem, cada uma das quarenta e cinco questões é classificável de forma mutuamente excludente em uma das três disciplinas universalmente reconhecidas: Física, Química e Biologia. Esta acaciana constatação evidencia o fracasso na realidade do Ensino Médio da pretensa interdisciplinaridade.

Preponderam nas duas últimas edições do Enem questões de Mecânica (13 em 30 questões) e NENHUMA questão de Física Moderna!

Soma-se aos equívocos da interdisciplinaridade e à prevalência de temas de Mecânica, a BAIXA QUALIDADE DAS QUESTÕES de Física no Enem, decorrente, em alguma medida, da exigência de que TODAS as questões devam ser contextualizadas. A tentativa de "contextualização a qualquer custo" leva a proposição de esdrúxulas "situações do cotidiano", como, por exemplo, a questão 85 da prova de Ciências da Natureza, caderno azul do Enem 2013, que apresenta inúmeras respostas possíveis (e não apenas uma), conforme discutido no Anexo.

Encontram-se também questões que padecem de outros vícios, além da "contextualização a qualquer custo". Um exemplo de tal tipo de questão é a Questão 77 da prova de Ciências da Natureza, caderno azul do Enem 2012, também discutida no Anexo.

O professor Fernando Lang da Silveira, do Instituto de Física da UFRGS, identificou diversas questões, em edições recentes do Enem, com vícios iguais ou piores do que estes aqui apresentados. Apesar de encaminhar por duas vezes ao INSTITUTO NACIONAL DE ESTUDOS E PESQUISAS EDUCACIONAIS ANÍSIO TEIXEIRA (INEP), órgão responsável pelo Enem, seus comentários apontando os vícios e indicando a necessidade de anulação de algumas questões, somente recebeu lacônicas respostas dizendo que a comissão de especialistas responsáveis pelas questões confirmava a correção das mesmas e mantinha o gabarito

\footnotetext{
${ }^{1}$ Disponível em:

<http://www.sbfisica.org.br/v1/arquivos_diversos/noticias/abril2014/posicao-sbf-projetomudancas-curriculo-em-10042014.pdf >. Acesso em: 11 abr. 2014.

2 Disponível em:

<http://www.sbfisica.org.br/v1/arquivos_diversos/noticias/maio2014/carta-ao-INEP.pdf>. Acesso em: 16 jun. 2014.
} 
oficial para as respostas corretas. A íntegra dos comentários críticos sobre as questões de Física na prova de Ciências da Natureza de 2012 e 2013 se encontra disponível em:

〈http://www.if.ufrgs.br/ lang/Textos/Quest_Fisica.pdf>

$\mathrm{e}$

$\langle$ http://www.if.ufrgs.br/ lang/Textos/enem2013.pdf〉. Acessos em: 16 jun. 2014 .

Um artigo está publicado no Caderno Brasileiro de Ensino de Física sobre a absurda questão da garrafa pet na edição de 2013 do Enem ${ }^{3}$.

No dia 26 de março de 2014, o professor Fernando Lang da Silveira participou como palestrante dos Colóquios sobre o Enem e a reformulação do Ensino Médio ${ }^{4}$ no INEP, em Brasília, reiterando suas críticas ao Enem. A íntegra do documento que orientou sua palestra se encontra em $\langle$ http://www.if.ufrgs.br/ lang/Textos/Ancritquestfis_INEP.pdf〉. Acesso em: 11 abr. 2014.

Após a sua apresentação, não ouviu dos representantes do INEP qualquer tentativa de rebater as críticas, embora não se dispusessem a anular as respectivas questões. O que lhe foi dito, então, entre outras colocações que tentavam justificar a má qualidade das questões, é que o INEP se eximia de responsabilidade pelos erros, já que as questões eram feitas por cerca de uma centena de professores universitários federais. A íntegra do relato sobre o que se passou no dia 24/03, seja pelo Professor Fernando Lang da Silveira, seja pelo organizador dos colóquios (funcionário técnico do INEP) se encontra disponível em <http://www.if.ufrgs.br/ lang/Textos/Relatorios.pdf>. Acesso em: 11 abr. 2014.

Seguiu-se a este primeiro colóquio a suspensão dos demais colóquios por prazo indeterminado!

Recentemente o INEP teve um novo diretor indicado, o Professor José Francisco Soares. Em entrevista à Folha de São Paulo (17/03/2014) o diretor manifestou a intenção "de explicitar de forma organizada, em algum tipo de portal, quais são as demandas cognitivas e pedagógicas das diferentes questões das pro-

${ }^{3}$ RODRIGUES, E. V. Uma revisão da questão da garrafa PET da prova do ENEM 2013. Caderno Brasileiro de Ensino de Física, v. 31, n. 2, p. 411-418, ago. 2014. Disponível em: $<$ https://periodicos.ufsc.br/index.php/fisica>.

4

Disponível em:

<http://www.if.ufrgs.br/ lang/Textos/2014_INEP_Coloquios_ENEM.pdf>. Acesso em: 16 abr. 2014.

Caderno Brasileiro de Ensino de Física, v. 31, n. 2, p. 473-479, ago. 2014. 
vas (...) organizar esse material com a lógica da instrução e dizer para o professor: está aqui algo que você pode utilizar".

A incompetência na formulação das questões de Física do Enem é complementada por irresponsabilidade intelectual e pedagógica quando o INEP não se mostra disposto a alterar os gabaritos oficiais do exame. Faz-se necessária a revisão dos gabaritos, ainda que tardiamente, pois qual lógica de instrução é possível de ser indicada aos professores para as questões mal formuladas se o INEP não reconhecer os erros? Que Física se pode ensinar utilizando-se questões com graves erros conceituais, se estes não forem identificados, reconhecidos e devidamente corrigidos?

\section{Anexo}

\section{Questão 85 da prova de Ciências da Natureza, caderno azul do Enem 2013:}

Desenvolve-se um dispositivo para abrir automaticamente uma porta no qual um botão, quando acionado, faz com que uma corrente elétrica $i=6 \mathrm{~A}$ percorra uma barra condutora de comprimento $L=5 \mathrm{~cm}$, cujo ponto médio está preso a uma mola de constante elástica $k=5 \times 10-2 N / \mathrm{cm}$. O sistema mola-condutor está imerso em um campo magnético uniforme perpendicular ao plano. Quando acionado o botão, a barra sairá da posição do equilíbrio a uma velocidade média de $5 \mathrm{~m} / \mathrm{s}$ e atingirá a catraca em 6 milisegundos, abrindo a porta.

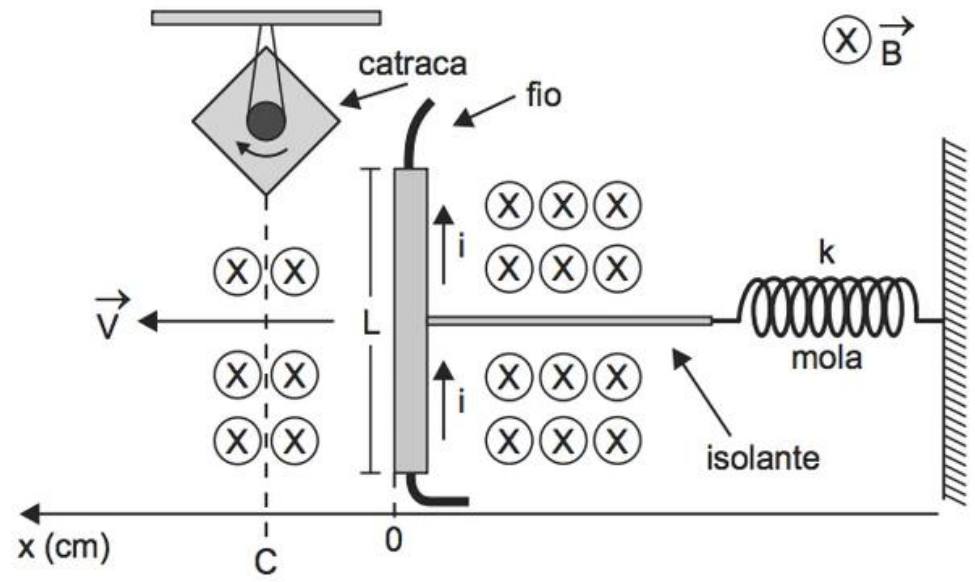

A intensidade do campo magnético, para que o dispositivo funcione corretamente, é de 

A) $5 \times 10^{-1} \mathrm{~T}$.
B) $5 \times 10^{-2} \mathrm{~T}$.
C) $5 \times 10^{1} \mathrm{~T}$.
D) $2 \times 10^{-2} \mathrm{~T}$.
E) $2 \times 10^{0} \mathrm{~T}$.

A questão 85 NÃO possui informações suficientes para que se chegue a uma ÚNICA resposta, pois a intensidade da força magnética NÃO está especificada para o momento de impacto. Se o enunciado da questão explicitasse o que se entende por "dispostivo funcione corretamente" talvez houvesse uma solução única para a questão.

Se supusermos que a intensidade da força magnética é 10 vezes a intensidade força elástica no instante do impacto (ou talvez igual à intensidade força elástica, ou talvez... sabe-se lá qual valor), então poderemos encontrar a intensidade do campo magnético (na verdade intensidade da INDUÇÃO MAGNÉTICA). Fazendo o cálculo com o fator 10 resulta

$$
\begin{gathered}
10 \times 0,15 \mathrm{~N}=6,0 \mathrm{~A} \times 0,05 \mathrm{~m} \times \mathrm{B}, \\
\mathrm{B}=5,0 \mathrm{~T} .
\end{gathered}
$$

Admitida outra hipótese, por exemplo, que a intensidade da força magnética seja igual à da força elástica, resultaria $\mathrm{B}=0,5 \mathrm{~T}$.

Se a intensidade da força magnética fosse igual a um décimo da intensidade da força elástica, resultaria $\mathrm{B}=0,05 \mathrm{~T}$.

E assim por diante...

As três possibilidades acima foram arbitrariamente calculadas. No gabarito oficial, a alternativa A $(0,5 \mathrm{~T})$ consta como correta, estando, portanto, subentendida a hipótese de que as forças magnética e elástica são iguais em intensidade no instante do impacto. Tendo-se em conta que o dispositivo deve produzir uma indução magnética uniforme sobre, no mínimo, uma região com área de $3,0 \mathrm{~cm}$ x $5,0 \mathrm{~cm}$ $=15 \mathrm{~cm}^{2}$ e dado que uma característica inelutável das questões do Enem é a "contextualização a qualquer custo", a terceira possibilidade $(\mathrm{B}=0,05 \mathrm{~T})$ é a mais realista! A produção de campos magnéticos com intensidade de $0,5 \mathrm{~T}$, cobrindo uma região com no mínimo $15 \mathrm{~cm}^{2}$ não é trivial de ser realizada. Campos com tal intensidade SOMENTE são encontrados no centro da face de super ímãs de neodímio!

A questão ainda possui um problema sério em relação à concepção do dispositivo mencionado. Que engenheiro, em sã consciência, projetaria o dispositi- 
vo dessa maneira, com essa geometria? Os dispositivos usados em portarias de prédios são eletromagnéticos, alimentados em corrente alternada, usando uma bobina para gerar o campo magnético alternado quando o botão é apertado. Se for para contextualizar, que se use uma situação realista, caso contrário é mais correto um enunciado na forma convencional, algo como: "Um fio de comprimento L fixado a uma mola de constante elástica k...".

De qualquer forma há MUITAS respostas possíveis (virtualmente infinitas) para esta questão!

\section{Questão 77 da prova de Ciências da Natureza, caderno azul do Enem 2012:}

Um consumidor desconfia que a balança do supermercado não está aferindo corretamente a massa dos produtos. Ao chegar a casa resolve conferir se a balança estava descalibrada. Para isso, utiliza um recipiente provido de escala volumétrica, contendo 1,0 litro d'água. Ele coloca uma porção dos legumes que comprou dentro do recipiente e observa que a água atinge a marca de 1,5 litro e também que a porção não ficara totalmente submersa, com 1/3 de seu volume fora d'água. Para concluir o teste, o consumidor, com ajuda da internet, verifica que a densidade dos legumes em questão é a metade da densidade da água, onde $\rho_{\text {agua }}=1 \mathrm{~g} / \mathrm{cm}^{3}$. No supermercado, a balança registrou a massa da porção de legumes igual a 0,500 kg (meio quilograma).

Considerando que o método adotado tenha boa precisão, o consumidor concluiu que a balança estava descalibrada e deveria ter registrado a massa da porção de legumes igual a
A) $0,073 \mathrm{~kg}$.
B) $0,167 \mathrm{~kg}$.
C) $0,250 \mathrm{~kg}$.
D) $0,375 \mathrm{~kg}$.
E) $0,750 \mathrm{~kg}$.

A QUESTÃO 77 “contextualiza” descontextualizando absurdamente, pois ninguém, em sã consciência, utilizaria o procedimento sugerido no enunciado para verificar se uma balança está calibrada. Algumas singelas razões para que este enunciado seja completamente irreal são:

1 - Como se mede a porção do volume de legumes que não ficou submer$\mathrm{sa}$ ? Ou, como se mede o volume total dos legumes?

2 - Quem, em sã consciência, acredita que uma especial classe de legumes possua densidade universalmente válida para todos os elementos dessa classe? 
Destaque-se, ainda, que esta questão padece de um enunciado contraditório. Se soubermos que o legume flutuante (o enunciado também não explicita se os legumes estão flutuando ou apoiados no fundo!) em água apresenta "l/3 de seu volume fora d'água", então, "a densidade dos legumes em questão NÃO é a metade da densidade da água", mas é $2 / 3$ da densidade da água.

Se creditada correção parcial do enunciado, isto é, admitindo-se como verdade que "Para isso, utiliza um recipiente provido de escala volumétrica, contendo 1,0 litro d'água. Ele coloca uma porção dos legumes que comprou dentro do recipiente e observa que a água atinge a marca de 1,5 litro.", então, a balança do supermercado está correta, pois tal informação é suficiente para afirmar que a massa dos legumes é aproximadamente $0,5 \mathrm{~kg}$. 